\title{
Genética en las ciencias de la salud
}

\author{
Genetics in health sciences
}

\author{
Iris C. López-Santillán ${ }^{a}$, Ma. Del Carmen A. Hernández-Ceruelos ${ }^{b}$, Juan D. Meza-Barrera $^{c}$, \\ Gloria M. Pérez-Escalante ${ }^{d}$, Víctor M. Muñoz-Pérez, ${ }^{e}$ Andrés Salas-Casas ${ }^{f}$,
}

Ana H. Figueroa Gutiérrez ${ }^{g}$

\begin{abstract}
:
Genetics has been greatly evolved the development of health sciences. Since Mendel's experiments to the current progress of technology for diagnosis, monitoring and treatment of genetic origin diseases. Moreover, it constitutes the basis of the structure for the knowledge of human genome and its variability on expression as the sustenance to keep the homeostasis as synonym of physical and mental health.
\end{abstract}

Keywords:

Genetics

\section{Resumen:}

La genética ha evolucionado enormemente el desarrollo de las ciencias de la salud. Desde los trabajos de Mendel hasta tener gran impactado en progreso de la tecnología actual para el diagnóstico, seguimiento y tratamiento de las enfermedades de origen genético. Además constituye las bases de la estructura, para el entendimiento del genoma humano y la variabilidad de su expresión, como el sustento para mantener el estado de homeostasis como sinónimo de salud física y mental..

\section{Palabras Clave:}

Genética

\section{Introducción}

La Genética constituye una rama de la biología que es esencial en el desarrollo de las ciencias asociadas, que en la actualidad tiene un desarrollo acelerado, a causa del impacto de las disciplinas genómicas. En los procesos educativos, a través de ella, se proporciona a los educandos las habilidades, actitudes y destrezas para lograr un mejor entendimiento de la organización de la información genética, así como sus efectos y mecanismos de regulación en los fenómenos de crecimiento, diferenciación y funcionamiento de tipo celular, tisular y orgánico del individuo.

Entre las aportaciones de esta disciplina destacan la esencia del conocimiento de las bases moleculares de la información genética y su control sobre la célula, permitiendo conocer la composición y organización de los ácidos nucleicos, tanto del ácido desoxirribonucléico (DNA) como del ácido ribonucleico (RNA) y sus formas, así como la diversidad de su conformación y localización en los organismos y virus. ${ }^{1,2,3,4}$

\footnotetext{
a Autor de Correspondencia, Universidad Autónoma del Estado de Hidalgo, Instituto de Ciencias de la Salud. ORCID: 0000-0003-07401539. Email: iris_lopez6859@uaeh.edu.mx

b Universidad Autónoma del Estado de Hidalgo, Instituto de Ciencias de la Salud. ORCID: 0000-0003-4065-4589 Email: alejandra.ceruelos@gmail.com

${ }^{\mathrm{c}}$ Universidad Autónoma del Estado de Hidalgo, Instituto de Ciencias de la Salud. Email: juandabek@gmail.com

d Universidad Autónoma del Estado de Hidalgo, Instituto de Ciencias Económico Administrativas. ORCID: 0000-0002-6348-6488 Email: gloria_perez7523@uaeh.edu.mx

Universidad Autónoma del Estado de Hidalgo, Instituto de Ciencias de la Salud. ORCID: 0000-0003-1820-0839 Email: victor_munoz9783@uaeh.edu.mx

${ }^{\mathrm{f}}$ Universidad Autónoma del Estado de Hidalgo, Instituto de Ciencias de la Salud. ORCID: 0000-0001-5930-2984 Email: andres_salas15@yahoo.com.mx

g Universidad Autónoma del Estado de Hidalgo, Instituto de Ciencias de la Salud. ORCID: https: 0000-0002-8424-9481 Email: ana_figueroa3494@uaeh.edu.mx
} 
El procesamiento de la información genética durante el ciclo celular, es estudiado a través de las estructuras normales y anormales por medio del discernimiento de la regulación de su segregación y distribución en las divisiones celulares derivadas del ciclo celular, para concretar en los procesos de mitosis y meiosis. ${ }^{1,2,3}$

El estudio del dogma central de la genética, nos permite explicar los procesos moleculares para que se efectúe la expresión y regulación genética, a través de la Replicación, la Transcripción, la Maduración y la Traducción de los ácidos nucleicos, que nos explican los procesos de duplicación del DNA y expresión genética. $^{1,2,3,4}$

Por otro lado, la genética celular o citogenética permite, distinguir y clasificar a cada cromosoma utilizando, entre otras, las técnicas de bandeo cromosómico, que hacen posible la identificación precisa de los cromosomas dentro del cariotipo humano. Lo anterior se efectúa principalmente en la medicina, con la finalidad de realizar diagnósticos para determinar la existencia o no de aberraciones cromosómicas, las cuales son alteraciones en los cromosomas. Las aberraciones pueden ser de tipo numérico como son las aneuploidías y poliploidías o euploidías, o de tipo estructural y pueden ser causa de problemas en la salud como pueden ser la formación de embarazos molares, los abortos espontáneos o algunos síndromes. De éstos últimos podemos mencionar algunos ejemplos provocados por anomalías numéricas, como pueden ser los Síndromes de: Down o trisomía 21, el de Edwards o trisomía 18, de Patau o trisomía 13, de Klinefelter o trisomía gonosómica XXY, de Turner 0 monosomía $X$, de Superhembra o trisomía $X$ y la trisomía $\mathrm{XYY}$, como los síndromes de más comunes en seres humanos. Para el caso de las anomalías estructurales, relacionadas con la presencia de síndromes, los relevantes con relación a su prevalencia son los sídromes causados por deleciones, como son los síndromes de Cri Du Chat, Wolf-Hirschhorn, Di George, a los que se suma el Síndrome de $X$ frágil, que es la causa principal de retraso mental en seres humanos, y que es causado por un fenómeno conocido como expansión de tripletas. ${ }^{1,2,3}$

Asimismo, la citogenética facilita el entendimiento de los mecanismos de formación de dichas aberraciones y proporciona la nomenclatura adecuada, basándose en las reglas internacionales de código de nomenclatura citogenética internacional (ISCN). ${ }^{1,2,3}$

Una de las principales aportaciones de la genética, es el conocimiento de los mecanismos de herencia, actualmente subdivididos en clásicos y no clásicos. Las aportaciones de Mendel realizadas en 1865, siguen constituyendo el sustento de los mecanismos de acción de los genes y sirven para discernir entre los distintos tipos de manifestación de enfermedades genéticas, que nos permite clasifican en Herencias autosómicas dominante y recesiva, Codominantes y Gonosómicas, ya sea ligadas al cromosoma $X$ de forma dominante $y$ recesiva $\mathrm{O}$ al cromosoma $\mathrm{Y}$, conocida también como herencia holándrica. Por otro lado, existen también las formas de herencia no clásica, que no se rigen por las leyes descritas por Mendel, las cuales pueden ser, entre otras, de tipo Mitocondrial, por Expansión de Tripletas, por Disomía uniparental o por Impronta Genómica. 1,2,3

Las aplicaciones tecnológicas de la Genética han abierto la posibilidad de la identificación de características normales y de alteraciones de la información genética, así como la intervención del ser humano en su manipulación. El diagnóstico de enfermedades genéticas se sirve de técnicas como el Tamíz metabólico, el diagnóstico prenatal, neonatal y del adulto, así como su tipificación por técnicas moleculares como la electroforesis, la reacción en cadena de la polimerasa (PCR), las técnicas de Bloteo (BLOTs), la hibridación fluorescente in situ (FISH), la secuenciación, los microarreglos, entre otras. Todo esto, nos permite el diagnóstico de enfermedades entre las que se encuentran los errores innatos del metabolismo, las de proteínas de tipo estructural, receptoras y de transporte, y los priores. ${ }^{2,3}$

Las nuevas tecnologías han impulsado el desarrollo de la Medicina Genómica y la aplicación de recursos terapéuticos para mejorar la calidad de vida de los pacientes con enfermedades de origen genético, además de brindar apoyo en la toma de decisiones a través del Consejo Genético. Además de la medicina, las áreas de ciencias de la salud, como la nutrición y la psicología, están vinculadas con un enfoque holístico en la prevención, la atención y el tratamiento de diversas enfermedades causadas por alteraciones en el genoma, ya sea de origen hereditario o de novo. Del mismo modo, se han ideado tecnologías de aplicación para la dilucidación del genoma y proteoma humano, la clonación celular, molecular y de individuos, la manipulación y aplicación terapéutica de células madre, así como los múltiples intentos en la búsqueda de una cura de enfermedades genéticas haciendo uso de las metodologías de la Terapia génica. 2,3 


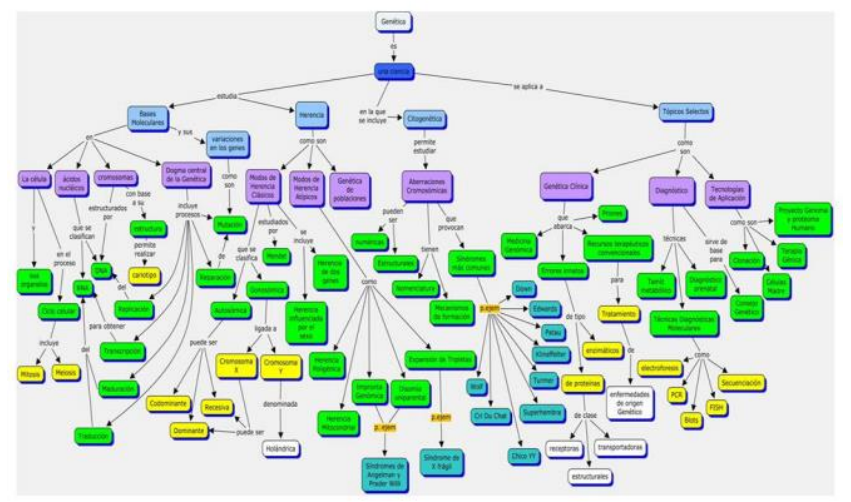

Figure 1. Mapa Conceptual de la Génética

Basándose en todo lo expuesto, la Genética fomenta la incorporación de los contenidos para la propedéutica clínica, la farmacología, la salud pública, la inmunología, la patología y la ética médica, entre otras disciplinas de las ciencias de la salud para integrar un adecuado diagnóstico, pronóstico y tratamiento de las enfermedades de origen genético.

\section{Referencias}

[1] Alberts B, Johnson A, Lewis J, Morgan D, Raff M, Roberts K, Walter P. Biología Molecular de la Célula. 6a ed. USA: Ediciones Omega; 2016

[2] Turnpenny P, Ellard S. Emery. Elementos de Genética Médica. 15a ed. España: Elsevier; 2018.

[3] Nusbaum RL, McInnes R., Willard H. Thompson \& Thompson. Genética Médica.8a ed. España: Elsevier; 2016.

[4] Krebs, J. Lewin's GENES XII. 12a ed. USA: Jones \& Bartlet Learning; 2018. 